\title{
Chemoreceptive foraging in a shallow-water scavenging lysianassid amphipod: role of amino acids in the location of carrion in Scopelocheirus onagawae
}

\author{
Keiichiro Ide ${ }^{1, *}$, Kazutaka Takahashi ${ }^{1}$, Toshiki Nakano ${ }^{2}$, Minoru Sato ${ }^{2}$, Michio Omori ${ }^{2}$ \\ ${ }^{1}$ Tohoku National Fisheries Research Institute, 3-27-5 Shinhama, Shiogama, Miyagi 985-0001, Japan \\ ${ }^{2}$ Graduate School of Agricultural Science, Tohoku University, 1-1 Amamiya, Aoba, Sendai, Miyagi 980-0001, Japan
}

\begin{abstract}
Marine scavenging lysianassid amphipods depend on chemoreception for detecting carrion, a scarce resource, efficiently. This study focused on the chemoreceptive foraging of the scavenging amphipod Scopelocheirus onagawae using bioassay. Among the extracted fraction from flounder muscle, neutral and basic amino acids, especially glycine (Gly), alanine (Ala), and arginine (Arg), which are abundant in the tissues of marine animals, showed highly stimulatory effects. Synergism, the enhancement of the stimulatory efficiency by acidic amino acids (e.g. aspartic acid; Asp) that have minimal attractive effects as individual amino acids, was also observed. The threshold concentration of amino acids leading to a locomotory response was $10^{-7} \mathrm{~mol} \mathrm{l}^{-1}$, which is relatively low among crustaceans. The locomotory response at the threshold became more sensitive when amphipods were acclimatised to a lower concentration of amino acids $\left(8.0 \times 10^{-8} \mathrm{M}\right)$, suggesting that sensory adaptation is involved in their foraging. The chemoreceptive system in $S$. onagawae, i.e. the detection of common chemicals from animal tissue as feeding stimuli at low threshold concentrations, is advantageous in detecting a wide range of carrion prey items from a broad area. The high sensitivity, sensory adaptation and synergism by uncommon amino acids would be a beneficial adaptation for discriminating a food odour in an environment of chemical 'noise'. Since S. onagawae is a nocturnal suprabenthic forager, the sensitive chemoreceptive ability found in this study would be adaptive for detecting sparse and limited carrion items, the odour plume of which can reach their swimming layer, suggesting that this species is a specialised carrion feeder.
\end{abstract}

KEY WORDS: Amino acids · Sensory adaptation $\cdot$ Synergism $\cdot$ Behavioural threshold $\cdot$ Suprabenthic foraging $\cdot$ Scopelocheirus onagawae $\cdot$ Lysianassid amphipods $\cdot$ Japan

\section{INTRODUCTION}

Chemical cues permeate marine environments and are important factors controlling the behaviour of aquatic organisms such as larval settlement and metamorphosis (Pawlik 1986), courtship and mating (e.g. Gleeson 1982, Krång \& Baden 2004), and foraging (e.g. Rittschof 1980, Weissburg \& Zimmer-Faust 1993). In terms of foraging, the chemical signals that are transported as odour across relatively long distances could inform aquatic animals about the food quality, quantity, and location by its composition and concentration (e.g. Zimmer-Faust et al. 1988, Finelli et al. 2000). For example, nitrogenous compounds such as amino acids, ATP, and sugar are known to be feeding stimuli in decapod crustaceans (e.g. McLeese 1970, ZimmerFaust 1991). Generally, decapod crustaceans are physiologically able to detect these chemical stimuli at very low concentrations $\left(10^{-10}\right.$ to $\left.10^{-12} \mathrm{M}\right)$, however, their behavioural threshold concentration for initiating for- 
aging locomotion is several orders lower than the physiological one (Fuzessery et al. 1978, Derby \& Atema 1982, Zimmer-Faust \& Case 1983, Voigt \& Atema 1992). The more we know about the chemoreceptive ability of aquatic animals and their behavioural response to the signals, the better our understanding of their foraging strategy will be.

Marine scavenging amphipods belonging to the family Lysianassidae are assumed to depend largely on chemoreception for foraging (Sainte-Marie 1992, Britton \& Morton 1994). They numerically dominate the scavenger assemblage both in deep waters (Dahl 1979, Ingram \& Hessler 1983, Smith \& Baldwin 1984) as well as in shallow waters from temperate to polar regions (Biernbaum 1979, Sainte-Marie 1986a, Takekawa \& Ishimaru 2000, 2001), playing a key role in breaking-up and re-mineralising large food masses (i.e. carrion of invertebrates and vertebrates) within benthic ecosystems (Sainte-Marie 1992). Although the existence of obligate scavengers in marine ecosystems has been a matter of debate (Britton \& Morton 1994, Ruxton \& Houston 2004), the lysianassid amphipods contain potential candidate species (Kaiser \& Moore 1999, Ruxton \& Houston 2004). Rapid arrival of large numbers of the individuals to bottom-moored baits (Dayton \& Hessler 1972, Thurston 1979, Smith \& Baldwin 1982), and particular morphological and physiological characteristics (Dahl 1979, Smith \& Baldwin 1982) suggest that these amphipods are well adapted for a scavenging lifestyle.

Carrion is a scarce and ephemeral resource in most marine environments (Stockton \& DeLaca 1982, Sainte-Marie 1986a) and therefore scavenging amphipods have to detect and locate carrion efficiently. Although lysianassid amphipods have well developed antennule chemoreceptors (Dahl 1979, Kaufmann 1994), the mechanism by which they detect the carrion has yet to be extensively examined (but see Meador 1989, Tamburri \& Barry 1999). To date, Meador (1989) has made the most detailed study of chemoreception in a lysianassid amphipod. He found that Orchomene limodes showed a strong reaction to certain kinds of amino acids (e.g. taurine, tryptophan) that have little or no background concentration, and that the threshold concentration of amino acids required to induce locomotory behaviour in $O$. limodes was relatively high (order of $10^{-5} \mathrm{~mol} \mathrm{l}^{-1}$ ) among crustaceans. He concluded that the system (i.e. a response to chemicals which are uncommon in background at high threshold) is an adaptation to maximise the foraging efficiency in this small species (ca. $5 \mathrm{~mm}$ ) whose search area is limited, suggesting that $O$. limodes is a facultative (omnivore) scavenger (Meador 1989). However, this mechanism is somewhat contradictory of many field observations of other scavenging amphipods, characterised by swift and exclusive attraction to carrion, indicating that they are attracted from broad areas and have keen detection abilities (Sainte-Marie 1992).

The present study focused on the chemoreceptive foraging of the scavenging lysianassid amphipod Scopelocheirus onagawae Takekawa \& Ishimaru, 2000. This species is the dominant component among scavenging amphipod fauna inhabiting the shallow waters in Onagawa Bay, northeastern Japan (Takekawa \& Ishimaru 2000, 2001). Several tens of thousands of $S$. onagawae congregate on carrion and consume it within a short period of 2 to $3 \mathrm{~h}$ immediately after sunset in the field (Takekawa et al. 2004), indicating that this species is able to efficiently detect carrion, presumably by sensitive chemoreception. We performed the following laboratory experiments: first, a bioassay using extracts of flounder muscle and amino acids was conducted in order to identify the chemical feeding stimuli for this species; second, the sensitivity to respond to the stimuli was measured to determine the behavioural threshold concentration and sensory adaptation. Our study demonstrates that the chemoreceptive system of $S$. onagawae may be advantageous in detecting carrion originating from various animal species from a broad area.

\section{MATERIALS AND METHODS}

Collection and conditioning of animals. Scopelocheirus onagawae were collected with baited traps (Takekawa et al. 2004) over a rocky bottom about 25 to $30 \mathrm{~m}$ deep in Onagawa Bay, Japan $\left(38^{\circ} 25^{\prime} 00^{\prime \prime} \mathrm{N}\right.$, $141^{\circ} 30^{\prime} 10^{\prime \prime}$ E) from May through September 2004. Baited traps were deployed about $30 \mathrm{~cm}$ above the seabed overnight from 14:00 to 11:00 h. Each trap contained a fillet of saury Cololabis saira as bait. Collected individuals were immediately transferred to $50 \mathrm{l}$ plastic bags containing well aerated surface seawater. They showed scarcely any mortality during the $30 \mathrm{~min}$ transportation to the laboratory. Individuals were kept in an outdoor circular $200 \mathrm{l}$ tank with a flow of ambient seawater $\left(15\right.$ to $\left.20^{\circ} \mathrm{C}\right)$. The feeding condition of all animals used in this study was standardised as follows: they were satiated given access to saury fillet hung in the tank for $120 \mathrm{~min}$ (Ide et al. 2005). The amphipods were then kept in experimental chambers, having Nitex mesh $(1 \mathrm{~mm})$ to allow them something to cling onto to reduce stress (Chapelle \& Peck 1995), for $5 \mathrm{~d}$ before the following experiments without food.

Identification of feeding stimuli (bioassays). To identify the feeding stimuli for Scopelocheirus onagawae, we conducted a 2 phase bioassay: first, extracts from fish muscle were tested in order to determine the 
feeding stimuli in the field. In this assay, Japanese flounder, a common species occurring in this sea, was used for the extraction because muscle of this species showed a high attraction efficiency of amphipods in preliminary observations; second, stimulatory efficiency of single and combined amino acids in the extracted fraction was confirmed with commercially available reagents. All test substances were added to an agar block and the stimulatory efficiency of these substances was determined from the number of experimental individuals that aggregated onto the agar blocks. All substances were mixed with agar powder $\left(20 \mathrm{~g} \mathrm{l}^{-1}\right)$, boiled, transferred into film cases $(40 \mathrm{ml})$ and chilled. All agar blocks were prepared within $2 \mathrm{~h}$ of use. The experiments were run in the dark soon after sunset because $S$. onagawae is a nocturnally active forager (Takekawa et al. 2004, Ide et al. 2005). Plastic chambers $(1.5 \mathrm{l}, 15 \times 10 \times 10 \mathrm{~cm})$ were used for experiments with a seawater flow of $0.4 \mathrm{ml} \mathrm{s}^{-1}$. Each chamber accommodated 100 amphipods. An agar block containing a test substance was hung in the chamber (ca. 7 to $8 \mathrm{~cm}$ above the bottom) and the block was removed after $10 \mathrm{~min}$ to count the number of individuals which had aggregated onto the agar. No detachment of amphipods from the agar block was observed during the removal process. Each substance was tested in triplicate.

Preparations of test substances. Flounder muscle extracts: The procedure for fractionation of flounder muscle extracts is shown in Fig. 1. Japanese flounder Paralichthys olivaceus was stored at $-20^{\circ} \mathrm{C}$ and the white muscle was carefully isolated at $4^{\circ} \mathrm{C}$. We homogenised $200 \mathrm{~g}$ of the muscle in $500 \mathrm{ml}$ chloroform-ethanol solution and distilled water, and centrifuged it at $15000 \mathrm{rpm}(10000 \times \mathrm{g})$ for $10 \mathrm{~min}$ at $4{ }^{\circ} \mathrm{C}$ in order to obtain the lipid soluble and water-soluble fractions, respectively. No bioassay was made for the lipidsoluble fraction since no attraction to the fraction was observed in a preliminary experiment. The water-soluble fraction (WF) was filtered through a 10000 MW cut-off membrane filter (UK-10, Advantec) to obtain the filtrate fraction $(\mathrm{FF})$, the particulate fraction $(\mathrm{PF})$ remaining on the filter. Each fraction (WF, FF, and PF) was stored in a polycarbonate bottle filled with $\mathrm{N}_{2}$ gas, and refrigerated. The FF was used for further fractions.

The compounds of the FF were separated into 3 fractions: acidic fraction (AF), neutral fraction (NF) and basic fraction $(\mathrm{BF})$. The FF was applied to an anion exchange column $(4 \times 15 \mathrm{~cm}$, Dowex $1-\mathrm{X} 8, \mathrm{COOH}$ form). The column was washed with distilled water and the adsorbed compounds were eluted with $4 \mathrm{~N}$ $\mathrm{CH}_{3} \mathrm{COOH}$ (AF). The non-adsorbed compounds were combined, concentrated, and dissolved in distilled water. The $\mathrm{pH}$ was adjusted to 7.0, and the sample was applied to a cation-exchange column $(4 \times 15 \mathrm{~cm}$, Dowex 50W-X8, $\mathrm{NH}_{4}{ }^{+}$form) and washed with distilled water and non-adsorbed compounds were combined (NF). The adsorbed compounds were eluted with $3 \mathrm{~N}$ $\mathrm{NH}_{4} \mathrm{OH}(\mathrm{BF})$. In order to remove the buffer, these 3

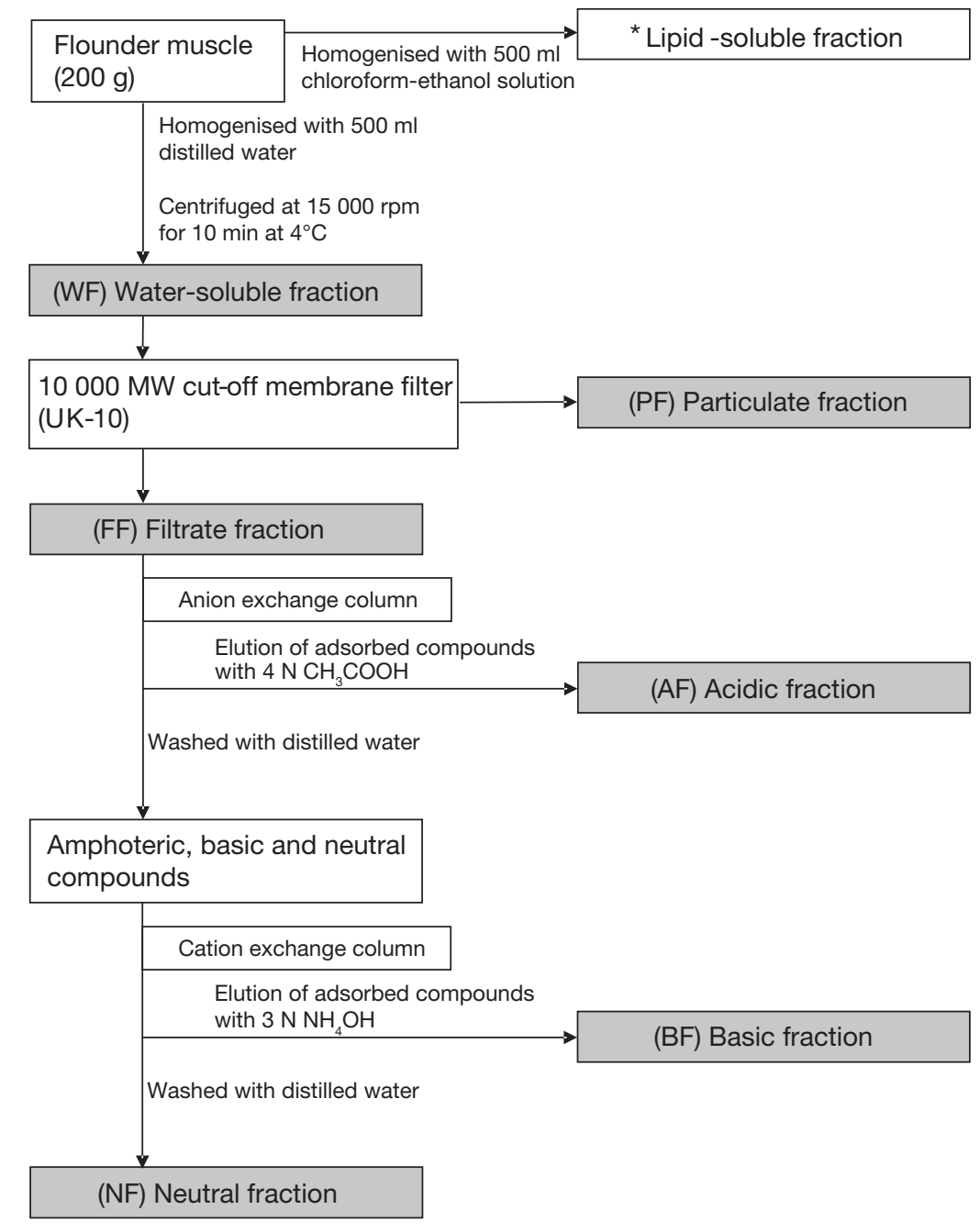

Fig. 1. Flow chart showing procedure for fractionation of flounder muscle extracts. Grey boxes indicate the fractions used in the bioassays. ${ }^{*}$ Lipid-soluble fraction was not used in the bioassay since no attraction was observed in preliminary observations 
fractions were concentrated and washed with distilled water several times. Consequently 6 fractions, WF, PF $\mathrm{FF}, \mathrm{AF}$, NF and BF, were obtained from flounder muscle and were tested in the bioassay.

Amino acids: To identify the substance responsible for feeding stimulation, a bioassay was also carried out with commercially available reagents of amino acids which compose the FF of flounder muscle (Fig. 1). The L-amino acids contained in the FF were analysed by HPLC after derivatisation to phenylthiocarbamyl amino acids by phenylisothiocyanate according to the method given in Sato et al. (1988, 1996) and concentrations of 13 amino acids in the FF (1500 mg dry $\mathrm{l}^{-1}$ ) were determined (Table 1). The amino acids in the FF were thus confirmed to be adequately separated by ion exchange chromatography. Out of the 13 amino acids in the FF, 10 dominant components (i.e. all but proline, valine and methionine) were tested in further bioassays with respective amino acids (Wako Pure Chemicals Industry). Single and combined amino acids were tested with the bioassay. Mimicked (artificial) FF, AF, NF and BF were prepared by adding amino acids at the concentrations deduced from amino acid analysis of the FF (Table 1) for the comparison with its corresponding fraction from flounder. Single amino acids were tested at an equimolar concentration of $2.3 \times 10^{-4} \mathrm{~mol} \mathrm{l}^{-1}$ which was the average concentration of 10 amino acid concentrations found in the FF (see Table 1). Combinations of neutral-basic, neutral-acidic, and basicacidic amino acids were also tested. Each amino acid was mixed at the same concentration as that found in the FF (Table 1).

Evaluation of the ability to detect amino acids. Two sets of experiments were carried out to determine: (1) the threshold concentration of amino acids that induces locomotory behaviour; and (2) the effect of increasing the amino acid concentration on amphipod behaviour. In both experiments, the number of swimming individuals was used as an index of the response. In order to detect slight differences of the locomotory response, both experiments were done within the $2 \mathrm{~h}$ before sunset, at which time Scopelocheirus onagawae does not leave the bottom of the experimental chambers without stimuli or perturbation. Although this species is a nocturnally active swimmer in the field (Takekawa et al. 2004), it normally responds and becomes active when food is offered even during the daytime under laboratory conditions (Ide et al. 2005).
Table 1. Concentrations of amino acids determined by HPLC in FF (1500 mg dry $\mathrm{l}^{-1}$ ) and their abbreviations. * Amino acids used in bioassays

\begin{tabular}{|c|c|c|}
\hline Substance & Abbreviation & $\begin{array}{c}\text { Concentration } \\
\left(\mathrm{mmol} \mathrm{l}^{-1}\right)\end{array}$ \\
\hline \multicolumn{3}{|c|}{ Acidic amino acids } \\
\hline Aspartic acid* & Asp & 0.201 \\
\hline Glutamic acid* & Glu & 0.188 \\
\hline \multicolumn{3}{|c|}{ Neutral amino acids } \\
\hline Serine $^{*}$ & Ser & 0.196 \\
\hline Glycine* & Gly & 0.361 \\
\hline Threonine* & Thr & 0.156 \\
\hline Alanine* & Ala & 0.220 \\
\hline Proline & Pro & 0.014 \\
\hline Valine & Val & 0.017 \\
\hline Methionine & Met & 0.011 \\
\hline Taurine ${ }^{*}$ & Tau & 0.594 \\
\hline \multicolumn{3}{|c|}{ Basic amino acids } \\
\hline Histidine $^{*}$ & His & 0.231 \\
\hline Arginine ${ }^{*}$ & Arg & 0.142 \\
\hline Lysine* & Lys & 0.510 \\
\hline
\end{tabular}

The bioassay apparatus was constructed as shown in Fig. 2. Seawater was supplied to Chamber 1, which was set to regulate the flow speed at $1.5 \mathrm{ml} \mathrm{s}^{-1}$, and then introduced through a silicon tube into Chamber 2, which accommodated 10 amphipods. The amino acid solution at the given concentration was injected into Chamber 1. The outlet of the silicon tube at Chamber 2 was placed on the bottom to ensure close proximity of stimuli to the animals, which rested on the bottom mesh. The test solution contained 10 amino acids in the same proportions and concentrations as those in the FF (Table 1).

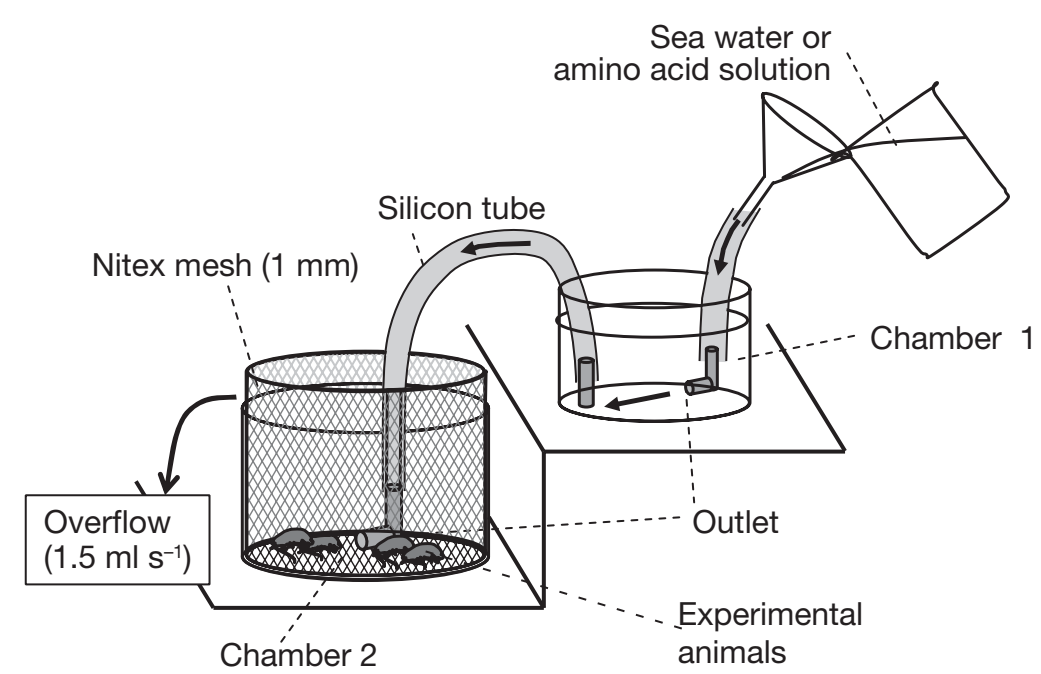

Fig. 2. Arrangement of experimental chambers for evaluation of the ability to detect amino acids. Arrows indicate the flow direction of seawater or test solution 
In Expt 1, the solution was injected into chamber 1 for $300 \mathrm{~s}$. The concentrations of each of the added amino acids were $9.5 \times 10^{-8}, 1.0 \times 10^{-7}, 3.5 \times 10^{-7}, 5.0 \times 10^{-7}, 7.0$ $\times 10^{-7}$ and $3.5 \times 10^{-6} \mathrm{~mol} \mathrm{l}^{-1}$. Seawater was also injected as a control. The background concentration of the 10 dominant amino acids (Table 1 ) in seawater was $2.0 \times$ $10^{-8} \mathrm{~mol} \mathrm{l}^{-1}$ (H. Ogawa \& N. Saotome pers. comm.). In Expt 2, the concentration of amino acids applied was elevated every $60 \mathrm{~s}$ in the order of $1.0 \times 10^{-7}, 3.5 \times 10^{-7}$, $7.0 \times 10^{-7} \mathrm{~mol} \mathrm{l}^{-1}$. Two differently conditioned groups were used for Expt 2: Group 1 which had been acclimatised for $60 \mathrm{~s}$ at a lower amino acids concentration of 8.0 $\times 10^{-8} \mathrm{~mol} \mathrm{l}^{-1}$ before the injection of $1.0 \times 10^{-7} \mathrm{~mol} \mathrm{l}^{-1}$ solution, and Group 2 without such acclimatisation. No locomotory behaviour occurred during the acclimatisation process of Group 1. Triplicate tests were conducted for all treatments in both experiments.

Statistical analyses. ANOVA followed by Tukey's multiple comparison test $(p=0.05)$ was done to determine the stimulatory efficiency of fractions from flounder extracts and amino acids in the FF. The MannWhitney $U$-test $(p=0.05)$ was conducted to evaluate the influence of acidic amino acids on the stimulatory efficiency of individual amino acids. The influence of acclimatisation at a lower concentration of amino acids on the locomotory responses of amphipods was also tested with the Mann-Whitney $U$-test ( $p=0.05)$. All statistical analyses were carried out using an SPSS (v12.0) statistical package.

\section{RESULTS}

\section{Feeding stimuli}

WF and FF produced a similar proportion (80\%) of individuals congregating on the agar block (Fig. 3). The proportion for PF (7\%) was distinctly lower than that for the other 2 fractions (ANOVA, $F_{1,8}=328.177$, $\mathrm{p}<0.05)$. This indicates that the main chemical feeding stimuli for this species were in the water-soluble compounds with a molecular weight of less than $10 \mathrm{kDa}$ that were included in the FF.

The FF was divided into 3 fractions: $\mathrm{AF}, \mathrm{NF}$, and $\mathrm{BF}$ (Fig. 1). Among these fractions, the proportion of congregated individuals was highest in NF (55\%) followed by BF with about $40 \%$ (Fig. 4). In contrast, AF scarcely stimulated Scopelocheirus onagawae to feed (3\%).

Application of amino acid mixtures, which mimicked those found in flounder muscle extracts, invoked very similar responses to flounder muscle extract $(80 \%$ of animals congregated on the agar block) (Fig. 4). Neutral amino acid mixtures (Ser, Gly, Thr, Ala, Tau) were the most attractive $(60 \%)$, followed by basic amino

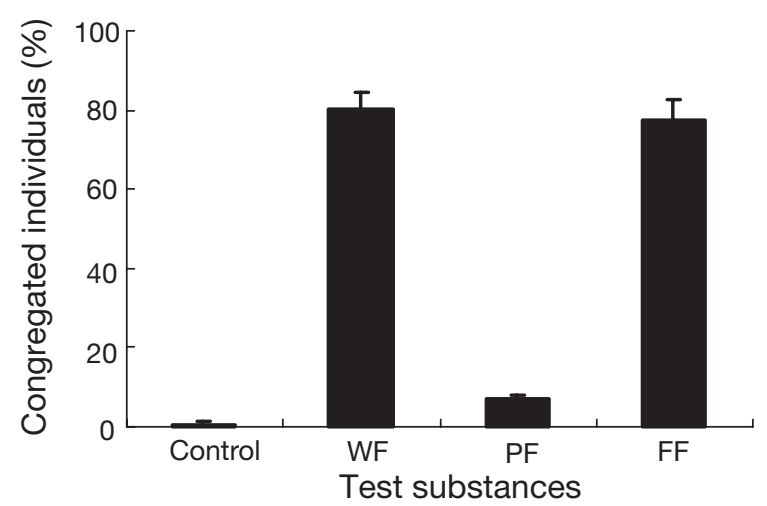

Fig. 3. Scopelocheirus onagawae. Congregated individuals onto agar blocks with water-soluble fraction (WF), particulate fraction (PF), and filtrate fraction (FF). Natural agar served as a control. Bars and error bars show means + SE

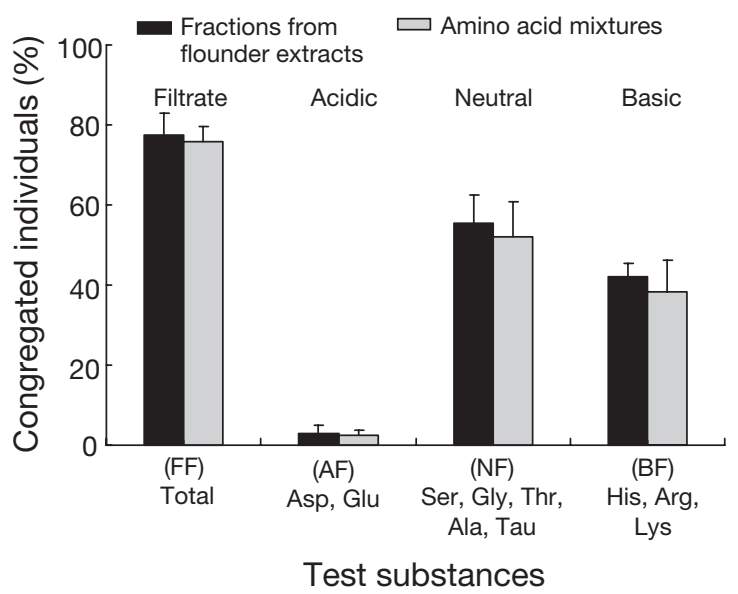

Fig. 4. Scopelocheirus onagawae. Mean congregated individuals onto agar blocks with the different 4 fractions from flounder extracts and corresponding amino acid mixtures. Error bars show standard errors. Total amino acids were mixed for the FF with 10 dominant amino acids (see Table 1). Asp, Glu mixture was for AF. Ser, Gly, Thr, Ala, Tau mixture was for NF. His, Arg, Lys mixture was for BF. Each amino acid was mixed at the same concentration as that found in FF (see Table 1)

acid mixtures (40\%) (His, Arg, Lys). Acidic amino acids (Asp, Glu) were scarcely attractive $(2 \%)$. (For definitions of amino acid abbreviations, please see Table 1.) These results confirmed that amino acids are the primary substances attracting amphipods to the flounder extracts.

In order to determine the stimulatory efficiency of single amino acids, the dominant 10 amino acids were tested individually (Fig. 5). Out of these, Gly, Ala, and Arg showed significantly higher stimulation (40 to $50 \%$ ) (ANOVA, $\left.F_{1,28}=94.680, \mathrm{p}<0.05\right)$. Various combinations of neutral-basic amino acids mixtures were also assayed (Fig. 6). The proportion of congregated 


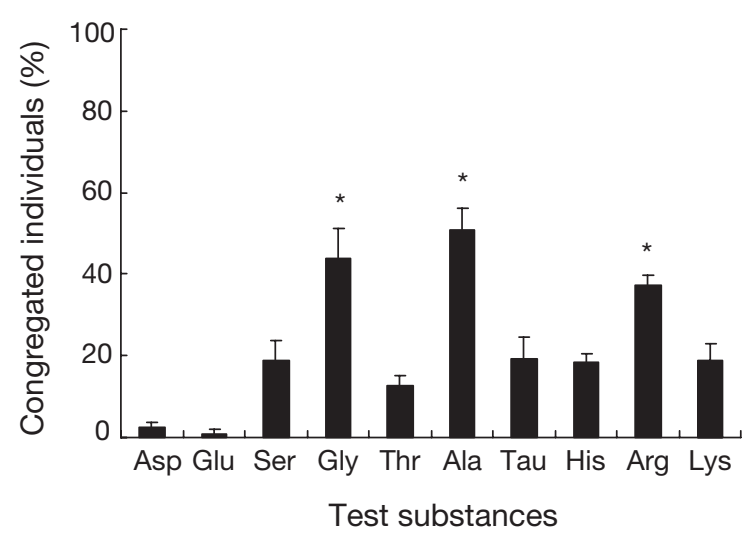

Fig. 5. Scopelocheirus onagawae. Mean congregated individuals onto agar blocks with different individual amino acids. Each amino acid was tested at an equimolar concentration of $2.3 \times 10^{-4} \mathrm{~mol} \mathrm{l}^{-1}$ (see 'Materials and methods' section). Error bars show standard errors. Asterisks indicate that means for Gly, Ala, and Arg were significantly higher than that for others (ANOVA, $F_{1,28}=94.680, \mathrm{p}<0.05$ )

individuals tended to increase with the increase of the number of combined amino acids to a maximum at $60 \%$ attraction.

The proportion of congregated Scopelocheirus onagawae responding to individual or mixtures of neutral and basic amino acids (ca. 40 to $60 \%$ ), however, did not reach the level found in the FF or corresponding amino acid mixtures (ca. $80 \%$ ). However, the stimulation efficiencies for the neutral and basic amino acids were enhanced dramatically by addition of acidic amino acids (Fig. 7). The enhancement caused by acidic amino acids was significant for all neutral and basic amino acids except for Lys (Mann-Whitney $U$ test, $\mathrm{p}<0.05)$. Particularly the 2 combinations of Gly, Asp and Ala, Asp attracted approximately $80 \%$ of the amphipods, i.e. similar to the level observed with the FF or for its corresponding amino acid mixture. Although significant enhancement by Glu was found for Ser and Thr (Mann-Whitney $U$-test, p < 0.05), the enhancement efficiency by Asp appeared to be higher than that by Glu.

\section{Response to variation in concentration of amino acids}

Changes in the proportions of swimming individuals and response times after injection of amino acids for 6 different concentrations and seawater (control) are shown in Fig. 8. At the 3 higher concentrations $(5.0 \times$ $10^{-7}, 7.0 \times 10^{-7}$ and $3.5 \times 10^{-6} \mathrm{~mol} \mathrm{l}^{-1}$ ), the proportion of swimming individuals rose sharply and reached $100 \%$ in the first $60 \mathrm{~s}$. At the lower concentrations, $3.5 \times 10^{-7}$, and $1.0 \times 10^{-7} \mathrm{~mol} \mathrm{l}^{-1}$, the proportion remained

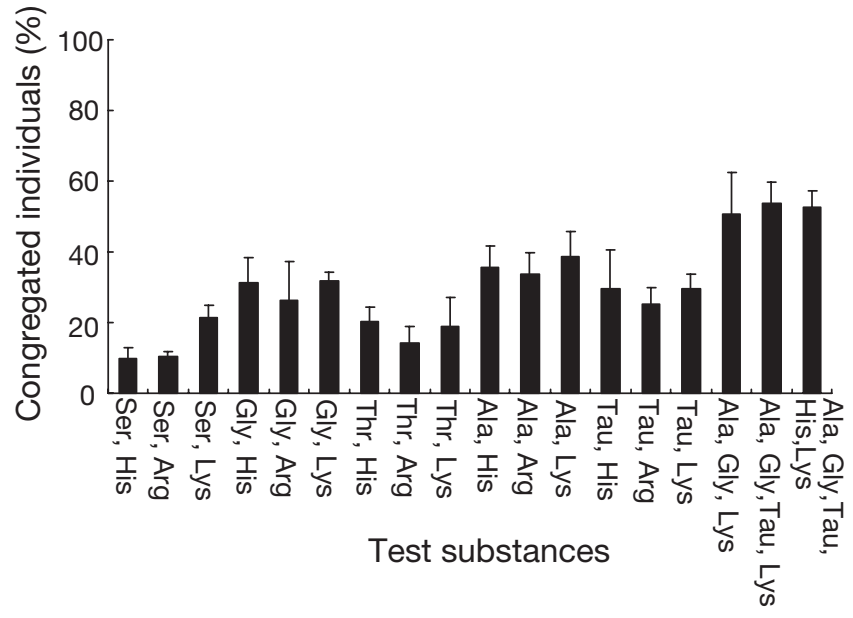

Fig. 6. Scopelocheirus onagawae. Mean proportion of congregated individuals onto agar blocks with neutral, basic amino acid mixtures. Error bars show standard errors. Each amino acid was mixed at the same concentration as that found in FF (see Table 1). Note that Ser, Gly, Thr, and Ala, Tau are neutral amino acids. His, Arg, and Lys are basic amino acids

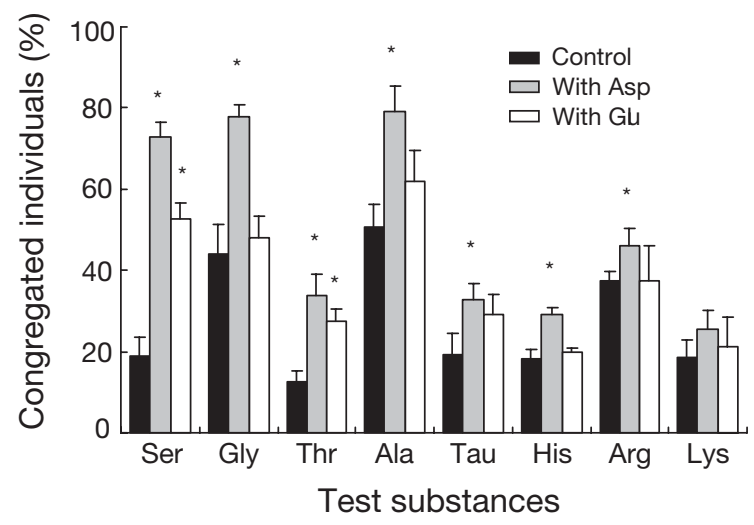

Fig. 7. Scopelocheirus onagawae. Mean congregated individuals onto agar blocks with neutral and basic amino acids mixed with Asp or Glu, as a single amino acid as the control. Each amino acid was mixed at the same concentration as that found in FF (see Table 1). Error bars show standard errors. Asterisks indicate that the means are significantly higher than that for corresponding individual amino acids as the control (Mann-Whitney $U$-test, $\mathrm{p}<0.05$ ).

between 30 and $60 \%$ in the first $120 \mathrm{~s}$. Few or no individuals swam at the lowest concentration of $9.5 \times 10^{-8}$ mol $\mathrm{l}^{-1}$ and in control seawater.

The response to increasing the amino acid concentration became more sensitive when the individuals were acclimatised at a lower amino acid concentration (Fig. 9). At concentrations of $1.0 \times 10^{-7}$ and $3.5 \times 10^{-7}$ mol $\mathrm{l}^{-1}$, the proportion of swimming individuals for Group 1 which was initially acclimatised for $60 \mathrm{~s}$ at a 


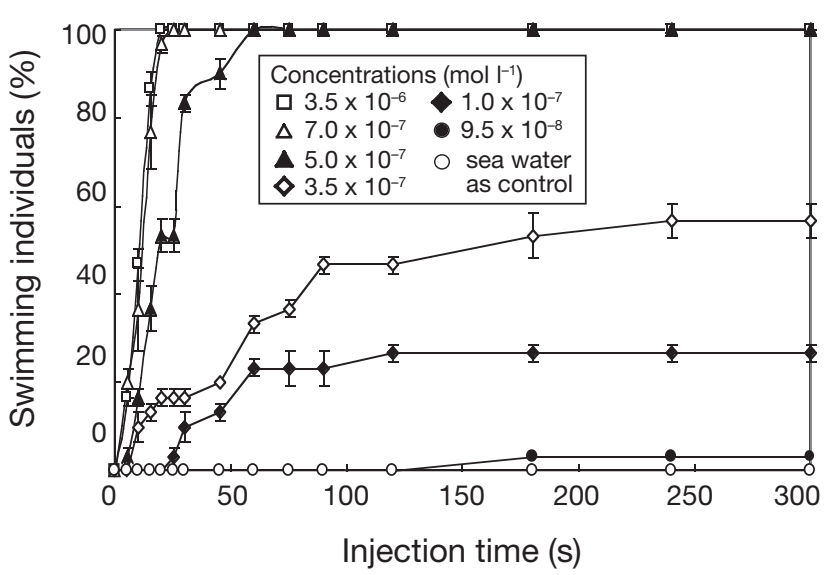

Fig. 8. Scopelocheirus onagawae. Change in swimming individuals against injection time at 6 different amino acids concentrations of $9.5 \times 10^{-8}, 1.0 \times 10^{-7}, 3.5 \times 10^{-7}, 5.0 \times 10^{-7}, 7.0 \times$ $10^{-7}, 3.5 \times 10^{-6} \mathrm{~mol} \mathrm{l}^{-1}$, and seawater as control. Mean proportions at respective concentrations are indicated as different symbols as shown in right box. Error bars show standard errors. The number of swimming individuals was counted every $10 \mathrm{~s}$

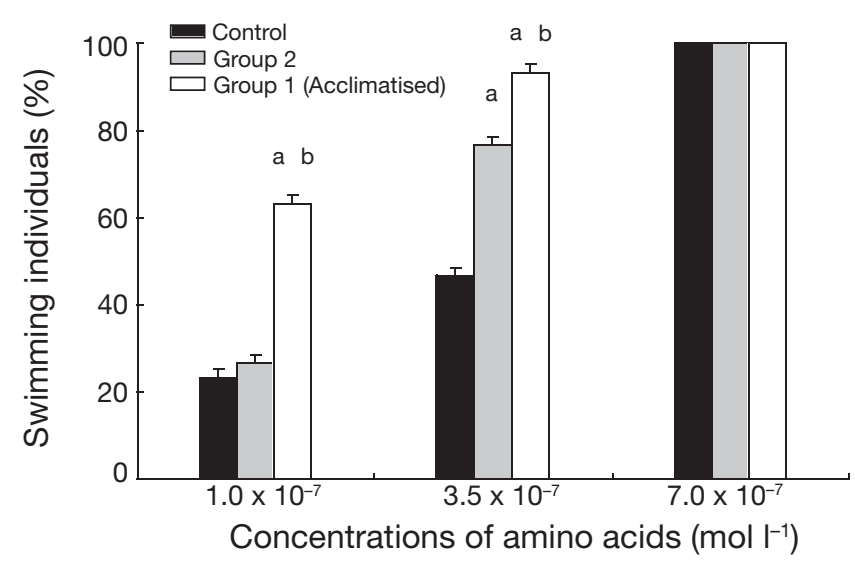

Fig. 9. Scopelocheirus onagawae. Mean swimming individuals in the consecutive elevation of amino acids concentrations. Error bars show standard error. Group 1 was acclimatised at a low concentration of $8.0 \times 10^{-8} \mathrm{~mol}^{-1}$; and Group 2 was not acclimatised. Control indicates the proportion of corresponding injected period $(60,120,180 \mathrm{~s})$ at relevant solutions without elevation of concentration (Fig. 8). Letters ' $a$ ' and 'b' show that means are significantly higher than that for corresponding controls, and for Group 2 respectively (MannWhitney $U$-test, $\mathrm{p}<0.05$ )

lower amino acid concentration $\left(8.0 \times 10^{-8} \mathrm{~mol}^{-1}\right)$ was significantly higher than those for Group 2 (nonacclimatised). In addition, the activities of amphipods to elevated amino acid concentrations (i.e. Groups 1 and 2) were higher than controls.

\section{DISCUSSION}

This study found that amino acids are the primary feeding stimuli for Scopelocheirus onagawae. In general, neutral and basic amino acids showed a stimulatory effect, and Gly, Ala, and Arg were particularly active (Fig. 5). Neutral and basic amino acids such as Gly, Ala, and Arg are abundant in the tissues of almost all marine animals such as flatworms, starfishes, gastropods, bivalves, crustaceans, cephalopods and fishes (Konosu \& Shinagawa 1988), and are therefore probably the main amino acids eluted into ambient seawater from dead or injured animals. It has been observed that $S$. onagawae is attracted to various dead marine animals including polychaetes, ascidians, blue mussels, scallops, sea snails, shrimps, crabs and flounders in a laboratory experiment (Ide 2005). These observations indicate that $S$. onagawae is able to detect and utilise the wide range of carrion from various animal species in the field.

The addition of acidic amino acids significantly enhanced the stimulatory efficacy of neutral and basic amino acids (Fig. 7), although they were not active when added in isolation (Fig. 5). Combinations of Gly, Asp and Ala, Asp were notably attractive (ca. 80\%). Such enhancement, i.e. synergism among amino acids or simple peptides, has been reported in decapod crustaceans (e.g. Zimmer-Faust et al. 1984) and fishes (e.g. Saglio et al. 1990) as well as in lysianassid amphipods (Meador 1989). The activity level of Orchomene limodes in response to a stimulant (a synthetic solution of common compounds mimicking mackerel tissue) can be enhanced by the addition of the tripeptide glutathione (Meador 1989); however, the ecological significance of this result has not been investigated. Generally Asp plays a role as an osmoregulatory chemical (Schoffeniels 1976). It is commonly found in the tissues of a variety of marine animals, but its concentration is relatively lower than those of Gly, Ala and Arg (Konosu \& Shinagawa 1988), suggesting that the dispersing area of eluted Asp from ruptured and decaying tissue would be more limited compared with other dominant amino acids. Furthermore, since Asp has a fairly low background concentration (ca. $4.0 \times$ $10^{-10} \mathrm{~mol} \mathrm{l}^{-1}$ in the study site; H. Ogawa \& N. Saotome pers. comm.) compared with other stimulant amino acids (ca. $2.0 \times 10^{-8} \mathrm{~mol}^{-1}$ at the study site), combined detection of Asp with stimulant amino acids may be a more reliable and stronger signal of the proximity of food to scavenging amphipods, resulting in the synergistic effect of enhancing locomotory activity.

The threshold concentrations of amino acids leading to a locomotory response in Scopelocheirus onagawae were about $10^{-7} \mathrm{~mol} \mathrm{l}^{-1}$ (Fig. 8), indicating that foraging behaviour is initiated by relatively low concentra- 
tions of amino acids. In comparison with other crustaceans (ca. $10^{-2}$ to $10^{-7} \mathrm{~mol} \mathrm{l}^{-1}$; e.g. McLeese 1970, Derby \& Atema 1982, Zimmer-Faust \& Case 1983) including Orchomene limodes $\left(10^{-5}\right.$ mol $\mathrm{l}^{-1}$; Meador 1989), S. onagawae has a relatively sensitive system for initiating foraging behaviour.

The locomotory response of Scopelocheirus onagawae to the feeding stimuli became more pronounced when they were first exposed to the consecutive elevations in amino acid concentration (Fig. 9). This phenomenon is considered to be a sensory adaptation, as reported in lobsters (e.g. Zimmer-Faust 1991). It is likely that $S$. onagawae interpret increases in amino acid concentration above those of background, as a reliable signal of the recent occurrence (or increasing proximity) of carrion, resulting in an enhancement of foraging activity. Since this phenomenon is also evident at the behavioural threshold concentration $(1.0 \times$ $10^{-7} \mathrm{~mol} \mathrm{l}^{-1}$ ) after the acclimatisation with low concentrations of amino acids $\left(8.0 \times 10^{-8} \mathrm{~mol}^{-1}\right)$, this sensory adaptation would be particularly beneficial to amphipods for the immediate detection of carrion occurrence against a low background amino acid concentration (e.g. oligotrophic environment) where the food odour would only be faintly above the behavioural threshold concentration.

Comparing the chemoreceptive system of Scopelocheirus onagawae with that of Orchomene limodes (Meador 1989), there seem to be 2 chemoreceptive foraging strategies among these shallow-water scavenging amphipods (Table 2). This difference is probably related to the spatial range of the food searching, which is directly involved with swimming activity. Stockton \& DeLaca (1982) hypothesised that species with low mobility should respond only to relatively undiluted chemical stimuli from nearby sources, because the probability of locating and sequestering food from a long way away is low. This hypothesis fits the case of O. limodes, the swimming ability of which is relatively poor due to its small size (ca. 5 mm; Meador 1989). In general, Orchomene and Orchomenella spp. are regarded as epibenthic crawlers that consistently prefer to forage for food along the bottom (Sainte-Marie 1986b, Tamburri \& Barry 1999, De Robertis et al. 2001). Within a spatially small range, uncommon chemicals in the background would be the most reliable and efficient stimulant for the detection and location of food (Meador 1989). Since the occurrence of large carrion is unlikely within any small spatial range (Sainte-Marie 1986a), species adopting an O. limodes-type chemoreception mechanism will probably be omnivorous scavengers in the field, consuming small but frequent carrion items as well as detritus or algae (Sainte-Marie 1986b, Meador 1989).

In contrast, the detection of common chemicals in animal tissues as feeding stimuli at a low threshold (Scopelocheirus-type) is obviously advantageous in finding and utilising a wide range of carrion from a broad area. S. onagawae is a nocturnally active swimmer that can even locate food in the baited traps at 0.5 to $2 \mathrm{~m}$ above the bottom (Takekawa et al. 2004, K. Ide unpubl. data), indicating that this species has a suprabenthic foraging pattern. Sainte-Marie (1986b) suggested that a suprabenthic foraging pattern in lysianassid amphipods results in selective attraction to large carrion items, because food odour from small carrion would not waft up to their swimming layer. High sensitivity to common amino acids, as found in the present study, is an essential factor enabling detection of carrion by this foraging pattern. Furthermore, because the substances stimulating feeding (Gly, Ala, Arg) are

Table 2. Scopelocheirus onagawae and Orchomene limodes. Chemoreceptive foraging and biological characteristics

\begin{tabular}{|c|c|c|}
\hline Term & $\begin{array}{l}\text { S. onagawae } \\
\text { (present study) }\end{array}$ & $\begin{array}{c}\text { O. limodes } \\
\text { (Meador 1989) }\end{array}$ \\
\hline Size & $10 \mathrm{~mm}$ & $5 \mathrm{~mm}$ \\
\hline \multicolumn{3}{|l|}{ Main feeding stimuli } \\
\hline Substances & Gly, Ala, Arg & Tau, tryptophan \\
\hline Distribution in animal taxa & Various & Local \\
\hline Concentration in seawater & Relatively high & Low or not detected \\
\hline \multicolumn{3}{|l|}{ Synergism } \\
\hline + Substances & + Asp & + Glutathione \\
\hline Concentration in seawater & low & low or not detected \\
\hline $\begin{array}{l}\text { Behavioural threshold } \\
\text { concentration }\end{array}$ & $10^{-7} \mathrm{~mol} \mathrm{l}^{-1}$ & $10^{-5} \mathrm{~mol} \mathrm{l}^{-1}$ \\
\hline Sensory adaptation & Present & Unknown \\
\hline Starvation tolerance & $60-75 \mathrm{~d}^{\mathrm{a}}$ & $10-15 d^{b}$ \\
\hline \multicolumn{3}{|l|}{ Habitat } \\
\hline Depth & $30-50 \mathrm{~m}$ & $50 \mathrm{~m}$ \\
\hline Temperature & $6-21^{\circ} \mathrm{C}$ & $7-15^{\circ} \mathrm{C}$ \\
\hline Bottom topography & Rocky & Sandy-rocky \\
\hline Locality & $\begin{array}{l}\text { gawa Bay, Pacific coast, } \\
\text { northeastern Japan }\end{array}$ & $\begin{array}{l}\text { Scripps Canyon, } \\
\text { Pacific coast, } \\
\text { Southern California }\end{array}$ \\
\hline \multicolumn{3}{|l|}{${ }^{\mathrm{a}} \mathrm{K}$. Ide pers. obs. } \\
\hline
\end{tabular}


often compounds found abundantly in the dissolved organic matter (DOM) of seawater (e.g. Clark et al. 1972, Zimmer-Faust 1991, Zimmer-Faust et al. 1999), the sensory adaptation and synergism by uncommon amino acids would also be an beneficial adaptation to discriminate food odour in an environment filled by chemical 'noise'.

Suprabenthic foraging behaviour in lysianassid amphipods involves some disadvantages, such as the risk of predation or extra energy expenditure (SainteMarie 1986a), although this behaviour is essential for encountering the odour from patchy and scarce large carrion (Sainte-Marie 1986b). Therefore, sensitive chemoreceptive ability, as seen in Scopelocheirus onagawae, is a necessary characteristic in suprabenthic scavenging lysianassid amphipods for the efficient detection of large carrion, which would therefore make them suitable candidates as specialised carrion feeders (Sainte-Marie 1992). Large carrion can be quantitatively and qualitatively excellent food if it can be detected and located fast, before other competitors gain access to it.

Acknowledgements. We are grateful to Captain T. Hiratsuka and other staff of the Education and Research Center of Marine Bio-resources, Tohoku University for their help in the field and laboratory works. We thank H. Ogawa and N. Saotome of the Ocean Research Institute, Tokyo University for measurements of amino acids concentration in seawater in Onagawa Bay. K. Sasaki of the Tohoku University provided valuable comments that helped us to improve an earlier version of the manuscript. Comments by H. Saito of the Tohoku National Fisheries Research Institute greatly improved this manuscript.

\section{LITERATURE CITED}

Biernbaum CK (1979) Influence of sedimentary factors on the distribution of benthic amphipods of Fishers Island Sound, Connecticut. J Exp Mar Biol Ecol 38:201-223

Britton JC, Morton B (1994) Marine carrion and scavengers. Oceanogr Mar Biol Annu Rev 32:369-434

Chapelle G, Peck LS (1995) The influence of acclimation and substratum on the metabolism of the Antarctic amphipods Waldeckia obesa (Chevreux 1915) and Bovallia gigantea (Pfeffer 1888). Polar Biol 15:225-232

Clark ME, Jackson GA, North WJ (1972) Dissolved free amino acids in southern California coastal waters. Limnol Oceanogr 17:749-758

Dahl E (1979) Deep-sea carrion feeding amphipods: evolutionary patterns in niche adaptation. Oikos 33:167-175

Dayton PK, Hessler RR (1972) Role of biological disturbance in maintaining diversityin the deep sea. Deep-Sea Res 19: 199-208

Derby CD, Atema J (1982) The function of chemo- and mechanoreceptors in lobster (Homarus americanus) feeding behavior. J Exp Biol 98:317-327

De Robertis A, Eiane K, Rau GH (2001) Eat and run: anoxic feeding and subsequent aerobic recovery by Orchomene obtusus in Saanich Inlet, British Colombia, Canada. Mar Ecol Prog Ser 219:221-227
Finelli CM, Pentcheff ND, Zimmer-Faust RK, Wethey DS (2000) Physical constraints on ecological processes: a field test of odor-mediated foraging. Ecology 81:784-797

Fuzessery ZM, Carr WES, Ache BW (1978) Antennular chemosensitivity in the spiny lobster, Panulirus argus: Studies of taurine sensitive receptors. Biol Bull 154: $226-240$

Gleeson RA (1982) Morphological and behavioral identification of the sensory structures mediating pheromone reception in the blue crab, Callinectes sapidus. Biol Bull 163:162-171

Ide K (2005) Feeding ecology of scavenging lysianassoid amphipod Scopelocheirus onagawae. PhD dissertation, Tohoku University, Sendai (in Japanese)

Ide K, Sasaki K, Omori M (2005) Food intake and digestion in the scavenging lysianassid gammaridean Scopelocheirus onagawae. Fish Sci 71:721-730

Ingram CL, Hessler RR (1983) Distribution and behavior of scavenging amphipods from the central North Pacific. Deep-Sea Res 30:683-706

Kaiser MJ, Moore PG (1999) Obligate marine scavengers: do they exist? J Nat Hist 33:475-481

Kaufmann RS (1994) Structure and function of chemoreceptors in scavenging lysianassoid amphipods. J Crustac Biol 14:54-71

Konosu S, Shinagawa A (1988) Nitrogenous compounds of invertebrates. In: Sakaguchi M (eds) Extractive components of fish and shellfish. Kouseisya Kouseikaku, Tokyo, p 81-101

Krång AS, Baden SP (2004) The ability of the amphipod Corophium volutator (Pallas) to follow chemical signals from con-specifics. J Exp Mar Biol Ecol 310:195-206

McLeese DW (1970) Detection of dissolved substances by American lobster (Homarus americanus) and olfactory attraction between lobsters. J Fish Res Board Can 27 : 1371-1378

Meador JP (1989) Chemoreception in a lysianassid amphipod: the chemicals that initiate food-searching behavior. Mar Behav Physiol 14:65-80

Pawlik JR (1986) Chemical induction of larval settlement and metamorphosis in the reef-building tube worm Phragmatopoma californica (Sabellariidae: Polychaeta). Mar Biol 91:59-68

Rittschof D (1980) Chemical attraction of hermit crabs and other attendants to simulated gastropod predation sites. J Chem Ecol 6:103-118

Ruxton GD, Houston CD (2004) Energetic feasibility of an obligate marine scavenger. Mar Ecol Prog Ser 266: 59-63

Saglio PH, Fauconneau B, Blanc JM (1990) Orientation of carp, Cyprinus carpio L., to free amino acids from tubifex extract in an olfactometer. J Fish Biol 37:887-898

Sainte-Marie B (1986a) Feeding and swimming of lysianassid amphipods in a shallow cold-water bay. Mar Biol 91: 219-229

Sainte-Marie B (1986b) Effect of bait size and sampling time on the attraction of the lysianassid amphipods Anonyx sarsi Steele \& Brunel and Orchomenella pinguis (Boeck). J Exp Mar Biol Ecol 99:63-77

Sainte-Marie B (1992) Foraging of scavenging deep-sea lysianassoid amphipods. In: Rowe GT, Pariente V (eds) Deep-sea food chains and the global carbon cycle. Kluwer, Dordrecht, p 105-124

Sato M, Suzuki S, Yasuda Y, Kawauchi H, Kanno N, Sato Y (1988) Quantitative HPLC analysis of acidic opines by phenylthiocarbamyl derivatization. Anal Biochem 174: 623-627 
Sato M, Nakano T, Takeuchi M, Kanno N, Nagahisa E, Sato Y (1996) Distribution of neuroexcitatory amino acids in marine algae. Phytochemistry 42:1595-1597

Schoffeniels E (1976) Adaptations with respect to salinity. Biochem Soc Symp 41:179-204

Smith KL, Baldwin JR (1982) Scavenging deep-sea amphipods: effects of food odor on oxygen consumption and a proposed metabolic strategy. Mar Biol 68:287-298

Smith KL, Baldwin JR (1984) Vertical distribution of the necrophagous amphipod, Eurythenes gryllus, in the North Pacific: spatial and temporal variation. Deep-Sea Res 31: 1179-1196

Stockton WL, DeLaca TE (1982) Food falls in the deep sea: occurrence, quality and significance. Deep-Sea Res 29: $157-169$

Takekawa A, Ishimaru S (2000) A new species of the genus Scopelocheirus (Crustacea: Amphipoda: Gammaridea) from Onagawa Bay, northeastern Japan. Zool Sci 17: 681-687

Takekawa A, Ishimaru S (2001) Two new species of the genus Anonyx (Amphipoda: Gammaridea: Lysianassoidea) from Onagawa Bay, northeastern Japan. Zool Sci 18:405-416

Takekawa A, Sasaki K, Omori M (2004) Daily activity and vertical distribution of lysianassoid amphipods dominant in Onagawa Bay, north-eastern Japan. Fish Sci 70:971-977

Tamburri MN, Barry JP (1999) Adaptations for scavenging by three diverse bathyal species, Eptatretus stouti, Neptunea

Editorial responsibility: Roger N. Hughes (Contributing Editor), Bangor, UK amianta and Orchomene obtusus. Deep-Sea Res I 46: 2079-2093

Thurston MH (1979) Scavenging abyssal amphipods from the north-east Atlantic Ocean. Mar Biol 51:55-68

Voigt R, Atema J (1992) Tuning of chemoreceptor cells of the 2nd antenna of the american lobster (Homarus americanus) with a comparison of 4 of its other chemoreceptor organs. J Comp Physiol A 171:673-683

Weissburg MJ, Zimmer-Faust RK (1993) Life and death in moving fluids: hydrodynamic effects on chemosensory mediated predation. Ecology 74:1428-1443

Zimmer-Faust RK (1991) Chemical signal-to-noise detection by spiny lobsters. Biol Bull 181:419-426

Zimmer-Faust RK, Case JF (1983) A proposed dual role of odor in foraging by the California spiny lobster, Panulirus interruptus (Randall). Biol Bull 164:341-353

Zimmer-Faust RK, Tyre JE, Michel WC, Case JF (1984) Chemical mediation of appetitive feeding in a marine decapod crustacean: the importance of suppression and synergism. Biol Bull 167:339-353

Zimmer-Faust RK, Stanfill JM, Collard SB (1988) A fast, multichannel fluorometer for investigating aquatic chemoreception and odor trails. Limnol Oceanogr 33: 1586-1595

Zimmer-Faust RK, Commins JE, Browne KA (1999) Regulatory effects of environmental chemical signals on search behavior and foraging success. Ecology 80:1432-1446

Submitted: October 28, 2005; Accepted: January 3, 2006 Proofs received from author(s): June 5, 2006 